\title{
Synthesis of Aryl Sulfides by Metal-Free Arylation of Thiols with Di- aryliodonium Salts
}

\author{
Sudeep Sarkar, ${ }^{\mathrm{a}, \mathrm{b}, \dagger}$ Natalia Wojciechowska, ${ }^{\mathrm{a}, \dagger}$ Adam A. Rajkiewicz, ${ }^{\mathrm{a}, *}$ and Marcin Kalek ${ }^{\mathrm{a}, *}$

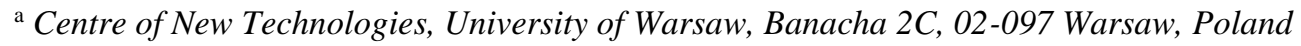 \\ ${ }^{\mathrm{b}}$ Faculty of Chemistry, University of Warsaw, Pasteura 1, 02-093 Warsaw, Poland
}

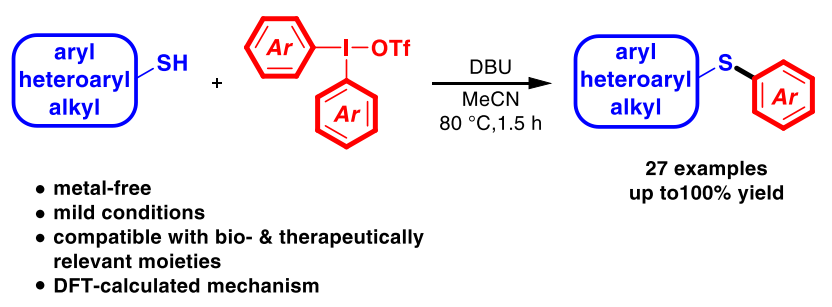

ABSTRACT: Metal-free arylation of thiols with diaryliodonium salts has been developed. The application of a strong organic base enables the $\mathrm{C}-\mathrm{S}$ bond formation under mild and experimentally simple conditions. The method allows for the synthesis of aryl sulfides containing a broad range of aryl groups from an array of thiols, including aryl, heteroaryl, and alkyl ones. The mechanism of the reaction was studied by DFT calculations, demonstrating that is follows the inner sphere pathway involving the incipient formation of $\mathrm{Ar} 2 \mathrm{I}(\mathrm{SR})$ intermediate, followed by the reductive elimination.

Aryl sulfide moiety is ubiquitous in natural products and bioactive molecules. ${ }^{1}$ These include several pharmaceuticals and drug candidates, exhibiting for example anti-Alzheimer, antiviral, antiinflammatory, and antidepressant activities (Figure 1). ${ }^{2}$ Moreover, aryl sulfides constitute important reagents for organic synthesis ${ }^{3}$ and building blocks in material chemistry. ${ }^{4}$
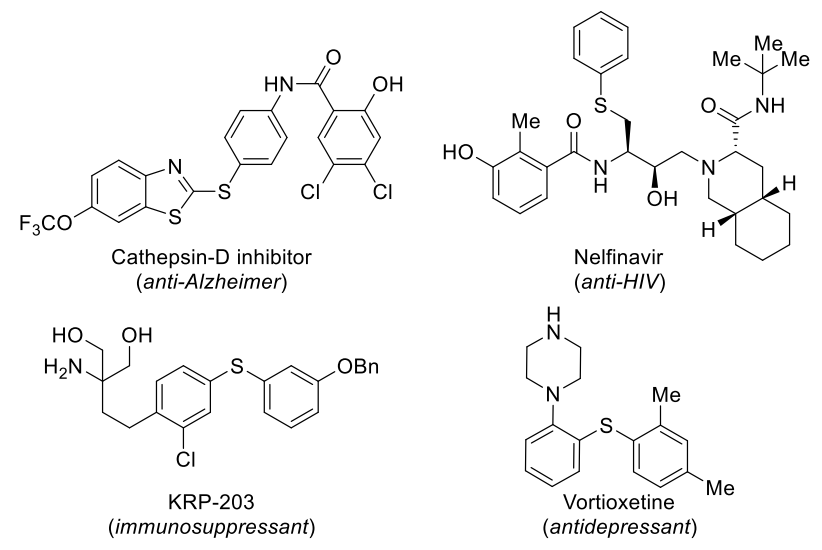

Figure 1. Examples of Bioactive Compounds Containing an Aryl Sulfide Moiety.

Among the existing methods for the preparation of aryl sulfides, the most general and widely used is the transition metalcatalyzed C-S cross-coupling. ${ }^{5}$ Complexes of a variety of metals, such as palladium, nickel, copper, cobalt, iron, gold, and indium, have been used as catalysts in these reactions. ${ }^{6}$ Apart from the typical couplings of aryl halides with thiols, oxidative and reductive variants also exist. ${ }^{7}$ Despite their high versatility, the inherent drawbacks of the transition metal catalyzed crosscouplings, especially in the context of pharmaceutical applications, are high price of the catalysts and possible contamination of products with trace metal residues. Therefore, the development of metal-free methods for the synthesis of aryl sulfides is an outstanding challenge and a number of such processes, for instance organocatalytic or photoinduced, has been recently reported. ${ }^{8}$ 


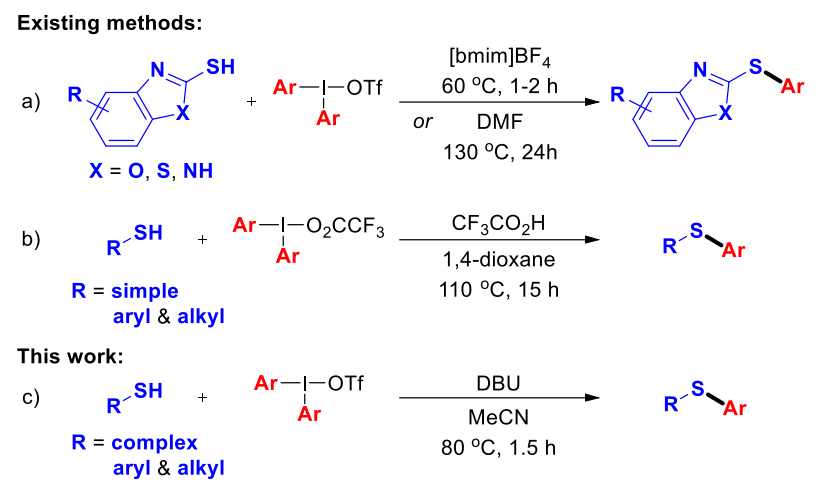

Scheme 1. Transition Metal-Free Synthesis of Aryl Sulfides Using Diaryliodonium Salts

One possible approach to eliminate the need of transition metal catalysis in Ar-S bond formation is the application of aryl transfer reagents based on hypervalent iodine. The steep downhill thermodynamics of I(III) to I(I) reduction has allowed for the arylation of various carbon and heteroatom nucleophiles (e.g., N-, O-, and P-centered) under metal-free conditions, however, the reports of aryl transfers to sulfur are scarce. ${ }^{9}$ In particular, as far as the synthesis of aryl sulfides from thiols is concerned, there exist only three such methods, employing diaryliodonium salts. Two of them, developed by Zheng and Chen, have the advantage of not requiring any extra reagents, but their scope is strictly limited to 2-mercaptobenzazole substrates (Scheme 1a). ${ }^{10}$ A more general procedure reported by Sanford utilizes an acid activation (Scheme 1b) ${ }^{11}$ Albeit it constituted a considerable advancement, that protocol is still restricted to simple thiols, mainly due to relatively harsh reaction conditions and long reaction times. Herein, we describe our work on an efficient metal-free arylation thiols with diaryliodonium salts (Scheme 1c). We hypothesized that the activation of the nucleophile by a base, commonly applied in other reactions employing hypervalent iodine group transfer reagents, ${ }^{9,12}$ may lead to a facile formation of aryl sulfides under mild conditions, allowing for the synthesis of complex products, relevant to pharmaceutical applications.

Table 1. Effect of Reaction Parameters

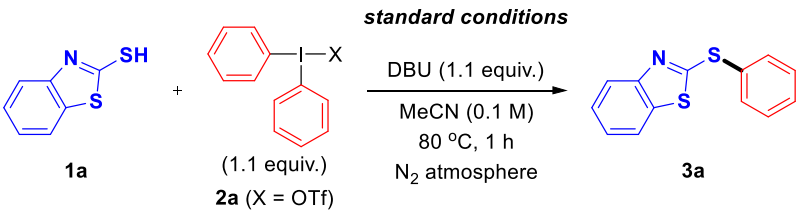

\begin{tabular}{lll}
\hline Entry & Change from the standard conditions & Yield (\%) $^{a}$ \\
\hline 1 & none & 95 \\
2 & TMG, instead of DBU & 99 \\
3 & Et 3 N, instead DBU & 87 \\
4 & $t$-BuOK, instead of DBU & 84 \\
5 & $\mathrm{AcONa}_{\text {, instead of DBU }} \mathrm{Cs}_{2} \mathrm{CO}_{3}$, instead of DBU & 91 \\
6 & $\mathrm{~K}_{3} \mathrm{PO}_{4}$, instead of DBU & 97 \\
7 & $\mathrm{NaHCO}_{3}$, instead of DBU & 34 \\
8 & pyridine, instead of DBU & 27 \\
9 & DABCO, instead of DBU & 56 \\
10 & toluene, instead of MeCN & 82 \\
11 & $\mathrm{DCE}$, instead of MeCN & 85 \\
12 & $\mathrm{CPME}$, instead of MeCN & 72 \\
13 & DMSO, instead of MeCN & 72 \\
14 & cyclohexane, instead of MeCN & 57 \\
15 & $\mathrm{X}=\mathrm{BF}$ (2b), instead of X $=$ OTf & 100 \\
16 & $\mathrm{X}=\mathrm{OOCCF}(\mathbf{2 c})$, instead of X $=$ OTf & 97 \\
17 & $\mathrm{X}=\mathrm{Cl}(\mathbf{2 d})$, instead of X $=$ OTf & 100 \\
18 & $\mathrm{X}=\mathrm{OTs}(\mathbf{2 e})$, instead of X $=$ OTf & 95 \\
19 & &
\end{tabular}


${ }^{a}$ Yields are average of two experiments and were determined by ${ }^{1} \mathrm{H}$ NMR spectroscopy; CPME $=$ cyclopentyl methyl ether, $\mathrm{DABCO}=1$,4-diazabicyclo[2.2.2] octane, $\mathrm{DBU}=1$,8-diazabicyclo[5.4.0] undec-7-ene, $\mathrm{DCE}=1$,2-dichloroethane, $\mathrm{TMG}=$ $\mathrm{N}, \mathrm{N}, \mathrm{N}^{\prime}, \mathrm{N}^{\prime}$-tetramethylguanidine.

Using 2-mercaptobenzothiazole (1a) and diphenyliodonium triflate (2a) as model substrates, we were able to establish a set of conditions for the S-arylation in quantitative yield (Table 1, entry 1). In particular, the reaction is carried out in the presence of DBU in acetonitrile at $80{ }^{\circ} \mathrm{C}$, under the atmosphere of nitrogen. The arylation also proceeds well with a range of other bases, both organic and inorganic (entries 2-7), however, these were later found to provide lower yields than DBU, when other starting materials were used. As far as solvents are concerned, application of toluene and DCE led to slightly decreased yields (entries 11-12), while further decline was observed for the other tested solvents (entries 13-15). We have also evaluated diphenyliodonium salts bearing various counter-anions, all of which delivered the product in excellent yields (entries 16-20). However, the use of phenylbenziodoxolone as the aryl transfer reagent had a detrimental effect on the reaction outcome (entry 21). Finally, it was determined that the efficiency of the arylation drops significantly at lower temperature (entry 22) and that the inert atmosphere is compulsory to attain quantitative product formation (entry 23).

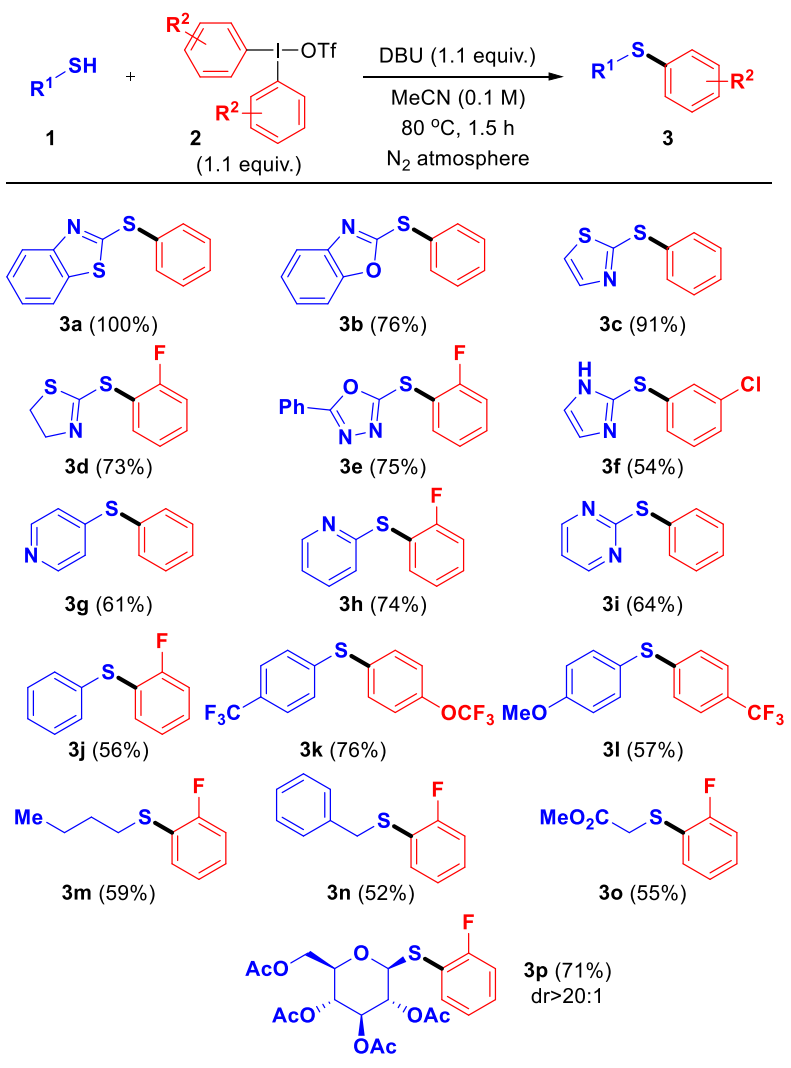

Scheme 2. Scope with Regard to the Thiol

Having optimized the reactions conditions, we explored the scope and limitations of this transition metal-free S-arylation of thiols. With regard to the thiol coupling partner (Scheme 2), good to excellent yields were obtained for five-membered heterocyclic thiols. These include thiols derived from pharmaceutically-relevant benzazoles $(\mathbf{3 a}, \mathbf{3 b}),{ }^{13}$ as well as thiazole (3c), 2-thiazoline (3d), and 1,3,4-oxadiazole (3e). 2-Mercaptoimidazole furnished the product with moderate efficiency (3f), likely due to the presence of a free $\mathrm{NH}$ group, although no aryl transfer to the nitrogen could be detected. The method is also applicable to the synthesis of aryl sulfides containing six-membered heterocycles, such as pyridine ( $\mathbf{3 g}, \mathbf{3 h})$ and pyrimidine (3i). The arylation of thiophenols is possible for unsubstituted, electron-poor, and electron-rich substrates (3j-3l). As far as the 
aliphatic thiols are concerned, they undergo the arylation under the developed conditions in somewhat lower, albeit still synthetically useful, overall yields compared to the aromatic counterparts. However, the reaction has proven to be quite general, tolerating starting materials ranging from simple alkyl (3m), through benzyl (3n), to functional group-containing (3o) thiols. Noteworthy, 1-thio- $\beta$-D-glucose derivative could be $S$-arylated in good yield (3p), demonstrating the usefulness of the method for the preparation of complex, biologically-relevant aryl sulfides.

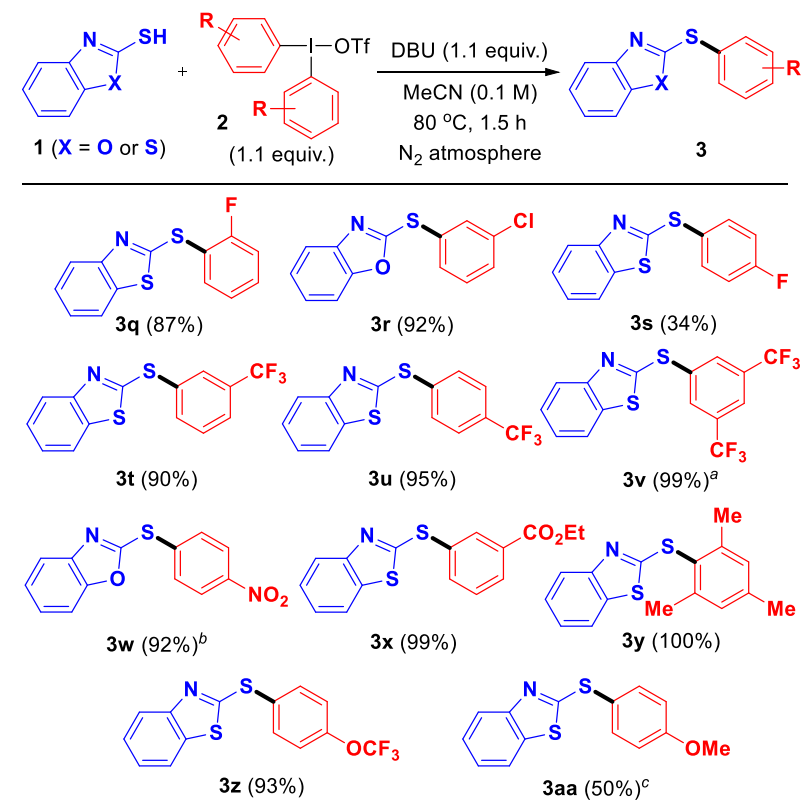

Scheme 3. Scope with Regard to the Diaryliodonium Salt. ${ }^{a}$ Synthesized using tetrafluoroborate salt; ${ }^{b}$ Synthesized using unsymmetrical (4-nitrophenyl)(phenyl)iodonium triflate; ${ }^{c}$ Synthesized using tosylate salt.

Next, we examined the scope with respect to diaryliodonium salts (Scheme 3). The reaction works well for 2- and 3-halide substituted aryl rings (3q, 3r), however, 4-fluorophenyl is transferred in a low yield (3s). All evaluated trifluoromethyl-containing aryl groups furnished desired sulfides with high efficiency $(\mathbf{3 t}-\mathbf{3 v})$, displaying the applicability of the developed methodology to prepare compounds of potential pharmaceutical interest. ${ }^{14}$ The presence of other electron-withdrawing substituents, such as nitro (3w) and ester (3x), also resulted in excellent yields of the corresponding products. Similarly, moderately electronrich aryls are well tolerated, as in the case of mesityl (3y) and 4-(trifluoromethoxy)phenyl (3z) moieties. The former example shows additionally that a considerable steric hindrance does not interfere with the $\mathrm{C}-\mathrm{S}$ bond formation. Only if a strongly electron-donating 4-methoxy substituent is present in the aryl ring, the efficiency of the coupling declines appreciably (3aa).

In order to obtain insight into the mechanism of the developed reaction, we performed DFT calculations (Figure 2). The computations show that in the presence of thiolate anion $\mathbf{4 a}$, diphenyliodonium triflate 2a is easily (via intermediate 5) and quantitatively transformed into a much more stable (by $7.2 \mathrm{kcal} / \mathrm{mol}$ ) iodonium thiolate species $\mathbf{6}$. The latter compound can undergo a $\mathrm{C}-\mathrm{S}$ bond-forming reductive elimination through TS1 with a viable barrier of $21.5 \mathrm{kcal} / \mathrm{mol}$, furnishing sulfide product 3a. In TS1, there exists a notable interaction between the nitrogen atom of the heterocyclic ring and iodine, likely lowering the barrier and resulting in the superior reactivity displayed by the heterocyclic thiol substrates (Scheme 2). The $\mathrm{C}-$ $\mathrm{S}$ bond-formation process, reducing iodine from + III to + I oxidation state and leading to the loss of hypervalency, is highly exergonic (by $35.0 \mathrm{kcal} / \mathrm{mol}$ relative to 6 ) providing the driving force for the reaction. We have also examined an alternative mechanistic pathway of a direct attack of thiolate nucleophile $\mathbf{4 a}$ on the aryl group of iodonium salt $\mathbf{2 a}$. However, the corresponding transition state, TS2, is found to have a prohibitively high energy barrier $(28.2 \mathrm{kcal} / \mathrm{mol}$ relative to $\mathbf{2 a})$. Therefore, the studied reaction follows preferentially the inner sphere pathway, reported for several other reactions employing iodine(III) group transfer reagents, ${ }^{15}$ rather than a less common direct substitution route, wherein iodine constitutes a leaving group. ${ }^{16}$ 


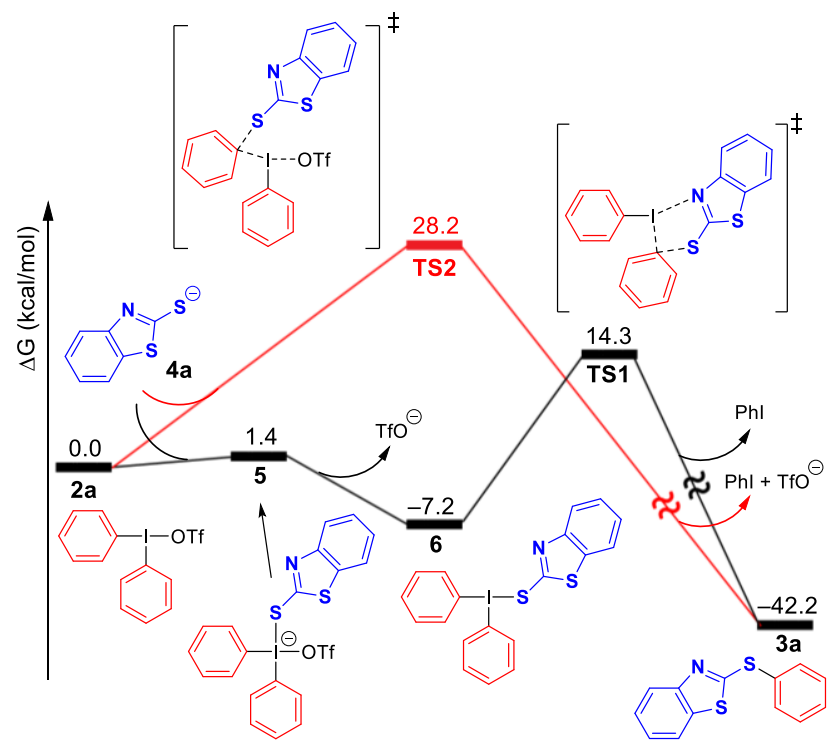

Figure 2. Calculated Free Energy Profile for the Arylation of Thiolate 4a with Diaryliodonium Salt 2a in Acetonitrile.

In summary, we have developed an efficient method for the synthesis of aryl sulfides by the arylation of thiols with diaryliodonium salts. The reaction proceeds without the need of metal catalysis, under mild conditions, and it is experimentally simple. It delivers a range of products containing various moieties, including pharmacophoric groups, such as heteroaryls and a sugar derivative. The performed DFT calculations demonstrate that the process follows an inner-sphere mechanism via $\mathrm{C}-\mathrm{S}$ bond-forming reductive elimination at iodine center.

\section{Supporting Information}

The Supporting Information file contains experimental procedures, characterization data and copies of NMR spectra for products, computational details and data

\section{ORCIDs \& e-mails}

Sudeep Sarkar - 0000-0003-1524-3411

Natalia Wojciechowska - 0000-0001-6653-0942

Adam A. Rajkiewicz - 0000-0002-9550-6287; E-mail: arajkiewicz@uw.edu.pl

Marcin Kalek-0000-0002-1595-9818; E-mail: m.kalek@cent.uw.edu.pl

\section{Author Contributions}

${ }^{\dagger}$ S.S. and N.W. contributed equally.

\section{Notes}

The authors declare no competing financial interest.

\section{ACKNOWLEDGMENT}

We acknowledge financial support from the National Science Centre, Poland (grant no. 2016/22/E/ST5/00566). Computer time was generously provided by the Interdisciplinary Centre for Mathematical and Computational Modeling of the University of Warsaw $(\mathrm{G} 75-0)$.

\section{REFERENCES}

(1) (a) Prinsep, M. R. Sulfur-Containing Natural Products from Marine Invertebrates. In Studies in Natural Products Chemistry, 1st ed.; Atta-ur-Rahman, Ed. Elsevier Science: 2003; pp 617-751. (b) Ilardi, E. A.; Vitaku, E.; Njardarson, J. T. Data-Mining for Sulfur and Fluorine: An Evaluation of Pharmaceuticals to Reveal Opportunities for Drug Design and Discovery. J. Med. Chem. 2014, 57, 2832-2842. (c) Tatsuta, T.; Hosono, M.; Rotinsulu, H.; Wewengkang, D. S.; Sumilat, D. A.; Namikoshi, M.; Yamazaki, H. Lissoclibadin 1, a Polysulfur Aromatic Alkaloid from the Indonesian Ascidian Lissoclinum $c f$. badium, Induces Caspase-Dependent Apoptosis in Human Colon Cancer Cells and Suppresses Tumor Growth in Nude Mice. J. Nat. Prod. 2017, 80, 499-502. 
(2) Selected examples: (a) Dumas, J.; Brittelli, D.; Chen, J.; Dixon, B.; Hatoum-Mokdad, H.; König, G.; Sibley, R.; Witowsky, J.; Wong, S. Synthesis and Structure Activity Relationships of Novel Small Molecule Cathepsin D Inhibitors. Bioorg. Med. Chem. Lett. 1999, 9, 2531-2536. (b) Hamada, M.; Kiuchi, M.; Adachi, K. Efficient Synthesis of the Immunomodulating Compound KRP-203. Synthesis 2007, 1927-1929. (c) Raghavan, S.; Krishnaiah, V.; Sridhar, B. Asymmetric Synthesis of the Potent HIV-Protease Inhibitor, Nelfinavir. J. Org. Chem. 2010, 75, 498-501. (d) Chen, G.; Højer, A.-M.; Areberg, J.; Nomikos, G. Vortioxetine: Clinical Pharmacokinetics and Drug Interactions. Clin. Pharmacokinet. 2018, 57, 673-686.

(3) Selected examples: (a) Sugahara, T.; Murakami, K.; Yorimitsu, H.; Osuka, A. Palladium-Catalyzed Amination of Aryl Sulfides with Anilines. Angew. Chem. Int. Ed. 2014, 53, 9329-9333. (b) Otsuka, S.; Yorimitsu, H.; Osuka, A. PalladiumCatalyzed Zinc-Amide-Mediated C-H Arylation of Fluoroarenes and Heteroarenes with Aryl Sulfides. Chem. Eur. J. 2015, 21, 14703-14707. (c) Rentner, J.; Kljajic, M.; Offner, L.; Breinbauer, R. Recent Advances and Applications of Reductive Desulfurization in Organic Synthesis. Tetrahedron 2014, 70, 8983-9027. (d) Lian, Z.; Bhawal, B. N.; Yu, P.; Morandi, B. Palladium-Catalyzed Carbon-Sulfur or Carbon-Phosphorus Bond Metathesis by Reversible Arylation. Science 2017, 356, 1059-1063. (e) Delcaillau, T.; Woenckhaus-Alvarez, A.; Morandi, B. Nickel-Catalyzed Cyanation of Aryl Thioethers. Org. Lett. 2021, 23, 7018-7022.

(4) (a) Rahate, A. S.; Nemade, K. R.; Waghuley, S. A. Rev. Chem. Eng. Polyphenylene Sulfide (PPS): State of the Art and Applications. 2013, 29, 471-489. (b) Boyd, D. A. Sulfur and Its Role In Modern Materials Science. Angew. Chem. Int. Ed. 2016, 55, 15486-15502. (c) Li, X.; Ma, W.; Li, H.; Zhang, Q.; Liu, H. Sulfur-Functionalized Metal-Organic Frameworks: Synthesis and Applications as Advanced Adsorbents. Coord. Chem. Rev. 2020, 408, 213191.

(5) Reviews: (a) Beletskaya, I. P.; Ananikov, V. P. Transition-Metal-Catalyzed C-S, C-Se, and C-Te Bond Formation via Cross-Coupling and Atom-Economic Addition Reactions. Chem. Rev. 2011, 111, 1596-1636. (b) Lee, C.-F.; Liu, Y.-C.; Badsara, S. S. Transition-Metal-Catalyzed C-S Bond Coupling Reaction. Chem. Asian J. 2014, 9, 706-722. (c) Shen, C.; Zhang, P.; Sun, Q.; Bai, S.; Hor, T. S. A.; Liu, X. Recent Advances in C-S Bond Formation via C-H Bond Functionalization and Decarboxylation. Chem. Soc. Rev. 2015, 44, 291-314.

(6) Selected examples: (a) Fernández-Rodríguez, M. A.; Shen, Q.; Hartwig, J. F. Highly Efficient and Functional-GroupTolerant Catalysts for the Palladium-Catalyzed Coupling of Aryl Chlorides with Thiols. Chem. Eur. J. 2006, 12, 77827796. (b) Wong, Y.-C.; Jayanth, T. T.; Cheng, C.-H. Cobalt-Catalyzed Aryl-Sulfur Bond Formation. Org. Lett. 2006, 8, 5613-5616. (c) Zhang, Y.; Ngeow, K. C.; Ying, J. Y. The First N-Heterocyclic Carbene-Based Nickel Catalyst for C-S Coupling. Org. Lett. 2007, 9, 3495-3498. (d) Sperotto, E.; van Klink, G. P. M.; de Vries, J. G.; van Koten, G. LigandFree Copper-Catalyzed C-S Coupling of Aryl Iodides and Thiols. J. Org. Chem. 2008, 73, 5625-5628. (e) Correa, A.; Carril, M.; Bolm, C. Iron-Catalyzed S-Arylation of Thiols with Aryl Iodides. Angew. Chem. Int. Ed. 2008, 47, 28802883. (f) Reddy, V. P.; Swapna, K.; Kumar, A. V.; Rao, K. R. Indium-Catalyzed C-S Cross-Coupling of Aryl Halides with Thiols. J. Org. Chem. 2009, 74, 3189-3191. (g) Jean, M.; Renault, J.; van de Weghe, P.; Asao, N. Gold-Catalyzed C-S Bond Formation from Thiols. Tetrahedron Lett. 2010, 51, 378-381. (h) Sayah, M.; Organ, M. G. Carbon-Sulfur Bond Formation of Challenging Substrates at Low Temperature by Using Pd-PEPPSI-IPent. Chem. Eur. J. 2011, 17, 11719-11722. (i) Uyeda, C.; Tan, Y.; Fu, G. C.; Peters, J. C. A New Family of Nucleophiles for Photoinduced, CopperCatalyzed Cross-Couplings via Single-Electron Transfer: Reactions of Thiols with Aryl Halides Under Mild Conditions $\left(0{ }^{\circ} \mathrm{C}\right)$. J. Am. Chem. Soc. 2013, 135, 9548-9552.

(7) Oxidative: (a) Joyce, L. L.; Batey, R. A. Heterocycle Formation via Palladium-Catalyzed Intramolecular Oxidative C-H Bond Functionalization: An Efficient Strategy for the Synthesis of 2-Aminobenzothiazoles. Org. Lett. 2009, 11, 27922795. (b) Xu, H.-J.; Zhao, Y.-Q.; Feng, T.; Feng, Y.-S. Chan-Lam-Type S-Arylation of Thiols with Boronic Acids at Room Temperature. J. Org. Chem. 2012, 77, 2878-2884. Reductive: (c) Ajiki, K.; Hirano, M.; Tanaka, K. RhodiumCatalyzed Reductive Coupling of Disulfides and Diselenides with Alkyl Halides, Using Hydrogen as a Reducing Agent. Org. Lett. 2005, 7, 4193-4195. (d) Arisawa, M.; Suzuki, T.; Ishikawa, T.; Yamaguchi, M. Rhodium-Catalyzed Substitution Reaction of Aryl Fluorides with Disulfides: $p$-Orientation in the Polyarylthiolation of Polyfluorobenzenes. J. Am. Chem. Soc. 2008, 130, 12214-12215.

(8) (a) Zou, L.-H.; Reball, J.; Mottweiler, J.; Bolm, C. Transition Metal-Free Direct C-H Bond Thiolation of 1,3,4-Oxadiazoles and Related Heteroarenes. Chem. Commun. 2012, 48, 11307-11309. (b) Chauhan, P.; Mahajan, S.; Enders, D. Organocatalytic Carbon-Sulfur Bond-Forming Reactions. Chem. Rev. 2014, 114, 8807-8864. (c) Hostier, T.; Ferey, V.; Ricci, G.; Gomez Pardo, D.; Cossy, J. Synthesis of Aryl Sulfides: Metal-Free C-H Sulfenylation of Electron-Rich Arenes. Org. Lett. 2015, 17, 3898-3901. (d) Liu, B.; Lim, C.-H.; Miyake, G. M. Visible-Light-Promoted C-S CrossCoupling via Intermolecular Charge Transfer. J. Am. Chem. Soc. 2017, 139, 13616-13619.

(9) (a) Yoshimura, A.; Zhdankin, V. V. Advances in Synthetic Applications of Hypervalent Iodine Compounds. Chem. Rev. 2016, 116, 3328-3435. (b) Olofsson, B., Arylation with Diaryliodonium Salts. In Hypervalent Iodine Chemistry, Wirth, T., Ed. Springer International Publishing: Cham, 2016; pp 135-166. (c) Chatterjee, N.; Goswami, A. Synthesis and Application of Cyclic Diaryliodonium Salts: A Platform for Bifunctionalization in a Single Step. Eur. J. Org. Chem. 2017, 2017, 3023-3032. (d) Ghosh, M. K.; Rajkiewicz, A. A.; Kalek, M. Organocatalytic Group Transfer Reactions with Hypervalent Iodine Reagents. Synthesis 2019, 51, 359-370. 
(10) (a) Wang, F.-Y.; Chen, Z.-C.; Zheng, Q.-G. Organic Reactions in Ionic Liquids: A Novel Method for the Synthesis of 2Arylthiobenzothiazoles by the S-Arylation of Benzolthiazole-2-Thiol with Diaryliodonium Salts. J. Chem. Res. 2004, 127-128. (b) Zhang, B.; Kang, Y.; Yang, L.; Chen, X. A S-Arylation of 2-Mercaptoazoles with Diaryliodonium Triflates under Metal-Free and Base-Free Conditions. ChemistrySelect 2016, 1, 1529-1532.

(11) Wagner, A. M.; Sanford, M. S. Transition-Metal-Free Acid-Mediated Synthesis of Aryl Sulfides from Thiols and Thioethers. J. Org. Chem. 2014, 79, 2263-2267.

(12) For examples of arylation of other sulfur nucleophiles with diaryliodonium salts under basic conditions, see: (a) Chen, Z.; Jin, Y.; Stang, P. J. Polyvalent Iodine in Synthesis. 2. A New Method for the Preparation of Aryl Esters of Dithiocarbamic Acids. J. Org. Chem. 1987, 52, 4117-4118. (b) Bátori, S.; Messmer, A. Regioselectivity in Methylation and Phenylation of the Zwitterionic Pyrido[2,1-f]-as-triazinium-1- and 3-olates and Thiolates. J. Heterocycl. Chem. 1988, 25, 437-444. (c) Xia, M.; Chen, Z.-C. Hypervalent Iodine in Synthesis XXII: A Novel Way for the Preparation of Unsymmetric S-Aryl Thiosulfonates by the Reaction of Potassium Thiosulfonates with Diaryliodonium Salts Synth. Commun. 1997, 27, 1309-1313. (d) Villo, P.; Kervefors, G.; Olofsson, B. Transition Metal-free, Chemoselective Arylation of Thioamides Yielding Aryl Thioimidates or $N$-Aryl Thioamides Chem. Commun. 2018, 54, 8810-8813.

(13) Azam, M. A.; Suresh, B. Biological Activities of 2-Mercaptobenzothiazole Derivatives: A Review. Sci. Pharm. 2012, 80, 789-823.

(14) (a) Huchet, Q. A.; Kuhn, B.; Wagner, B.; Kratochwil, N. A.; Fischer, H.; Kansy, M.; Zimmerli, D.; Carreira, E. M.; Müller, K. Fluorination Patterning: A Study of Structural Motifs That Impact Physicochemical Properties of Relevance to Drug Discovery. J. Med. Chem. 2015, 58, 9041-9060. (b) Gillis, E. P.; Eastman, K. J.; Hill, M. D.; Donnelly, D. J.; Meanwell, N. A. Applications of Fluorine in Medicinal Chemistry. J. Med. Chem. 2015, 58, 8315-8359. (c) Zhou, Y.; Wang, J.; Gu, Z.; Wang, S.; Zhu, W.; Aceña, J. L.; Soloshonok, V. A.; Izawa, K.; Liu, H. Next Generation of FluorineContaining Pharmaceuticals, Compounds Currently in Phase II-III Clinical Trials of Major Pharmaceutical Companies: New Structural Trends and Therapeutic Areas. Chem. Rev. 2016, 116, 422-518.

(15) (a) Norrby, P.-O.; Petersen, T. B.; Bielawski, M.; Olofsson, B. $\alpha$-Arylation by Rearrangement: On the Reaction of Enolates with Diaryliodonium Salts. Chem. Eur. J. 2010, 16, 8251-8254. (b) Malmgren, J.; Santoro, S.; Jalalian, N.; Himo, F.; Olofsson, B. Arylation with Unsymmetrical Diaryliodonium Salts: A Chemoselectivity Study. Chem. Eur. J. 2013, 19, 10334-10342. (c) Stridfeldt, E.; Lindstedt, E.; Reitti, M.; Blid, J.; Norrby, P.-O.; Olofsson, B. Competing Pathways in O-Arylations with Diaryliodonium Salts: Mechanistic Insights. Chem. Eur. J. 2017, 23, 13249-13258. (d) Ghosh, M. K.; Rzymkowski, J.; Kalek, M. Transition-Metal-Free Aryl-Aryl Cross-Coupling: C-H Arylation of 2-Naphthols with Diaryliodonium Salts. Chem. Eur. J. 2019, 25, 9619-9623.

(16) (a) Frei, R.; Wodrich, M. D.; Hari, D. P.; Borin, P.-A.; Chauvier, C.; Waser, J. Fast and Highly Chemoselective Alkynylation of Thiols with Hypervalent Iodine Reagents Enabled through a Low Energy Barrier Concerted Mechanism. J. Am. Chem. Soc. 2014, 136, 16563-16573. (b) Wodrich, M. D.; Caramenti, P.; Waser, J. Alkynylation of Thiols with Ethynylbenziodoxolone (EBX) Reagents: $\alpha$ - or $\beta$ - $\pi$-Addition? Org. Lett. 2016, 18, 60-63. (c) Rajkiewicz, A. A.; Wojciechowska, N.; Kalek, M. N-Heterocyclic Carbene-Catalyzed Synthesis of Ynones via C-H Alkynylation of Aldehydes with Alkynyliodonium Salts-Evidence for Alkynyl Transfer via Direct Substitution at Acetylenic Carbon. ACS Catal. 2020, 10, 831-841. 